\title{
ballot
}

\section{O devido processo legal e suas potencialidades $¥$ o caso do direito de voto dos negros nos Estados Unidos}

\author{
Marcelo Ramos Peregrino Ferreira (PUC-SP, Brasil) \\ peregrinoferreira@uol.com.br \\ Pontifícia Universidade Católica de São Paulo \\ Faculdade de Direito. Rua Ministro Godoi, 969 \\ Perdizes 05015-901 - Sao Paulo, SP - Brasil
}

Roberto Baptista Dias da Silva (PUC-SP, Brasil)

rdiasdasilva@pucsp.br 


\section{Resumo}

São apresentadas as definições do instituto do devido processo legal, da razoabilidade, da proporcionalidade e das suas fases históricas. Em seguida, demonstra-se que seu surgimento como emenda na Constituição dos Estados Unidos, vem com forte relação com o sufrágio negro nos Estados Unidos. E que o nascimento da equal protection clause foi motivada pela Guerra Civil estadounidense como continuidade dos esforços para a inclusão da população negra.

Palavras-chave: Devido processo legal; Cláusula de Isonomia; voto dos negros; Constituição dos Estados Unidos da América; proporcionalidade.

\section{Abstract}

We studied the due process of law from the idea of reasonable intervention to the proportionality requirement, that is, the substantial due process. Furthermore, the birth of this guarantee is examined in its relation with the black suffrage, in the beginning of the American Constitutional History, right at the Bill of Rights and the equal protection clause.

Keywords: Due Processo of Law; equal protection clause; Black Suffrage; United States Federal Constitution; Proportionality 


\section{Introdução}

Quando se fala em devido processo legal, o pensamento se dirige rapidamente às garantias do processo. Quando se fala em direito dos negros, surge, imediatamente, a ideia do direito à igualdade.

Mas qual é a relação entre devido processo legal e direito dos negros? Esta pergunta é que nos instiga neste ensaio. Pretendemos, neste artigo, voltar a atenção para concepções pouco usuais do devido processo legal, explorando a importância dele na luta dos direitos dos negros nos Estados Unidos da América. A ideia é mostrar que o devido processo legal, mais do que garantir direitos das partes nos processos judiciais ou administrativos, foi usado para combater o arbítrio estatal e, também, assegurar parcela do direito à igualdade.

Para chegar a essa constatação, trataremos, inicialmente, das concepções mais tradicionais do devido processo legal e, então, discutiremos o potencial que ele mostrou ter: um mais explorado no Brasil, que foi a força do devido processo legal substancial; e outro, quase ignorado entre nós, que se revelou como uma faceta da luta pela igualdade racial nos Estados Unidos da América.

\section{Devido processo legalः potencialidades}

Inicialmente, o devido processo legal se mostra como uma garantia processual (procedural due process), que assegura o direito ao contraditório, à ampla defesa, ${ }^{1}$ bem como o direito de ninguém ser julgado, senão por um juízo pré-constituído e competente para analisar o caso, ${ }^{2}$ e somente por fato definido anteriormente como crime, e com pena previamente estabelecida em lei. ${ }^{3}$ Também como decorrência do procedural due process surge o direito de ser assistido por um advogado e ter acesso ao Judiciário, mesmo sem possuir recursos financeiros para tanto. ${ }^{4}$

O sentido processual do devido processo legal aparece, de início, vinculado às garantias do processo penal e se estende à jurisdição civil para, posteriormente, alcançar os procedimentos administrativos. ${ }^{5}$

1. A Constituição Federal de 1988 prevê expressamente em seu art. 5, LV: "aos litigantes, em processo judicial ou administrativo, e aos acusados em geral são assegurados o contraditório e ampla defesa, com os meios e recursos a ela inerentes".

2. Os incisos XXXVII e LIII do art. $5^{\circ}$ da Constituição Federal estabelecem a garantia do juiz natural, e estão redigidos da seguinte forma, respectivamente: "não haverá juízo ou tribunal de exceção" e "ninguém será processado nem sentenciado senão pela autoridade competente".

3. A Constituição Federal prescreve, no art. 5 XXXIX: "não há crime sem lei anterior que o defina, nem pena sem prévia cominação legal".

4. Essas são as previsões contidas no art. 133 da Constituição Federal ("O advogado é indispensável à administração da justiça, sendo inviolável por seus atos e manifestações no exercício da profissão, nos limites da lei”), assim como as expressas no art. $5^{\circ}, \mathrm{XXXV}$ ("a lei não excluirá da apreciação do Poder Judiciário lesão ou ameaça a direito") e LXXIV ("o Estado prestará assistência jurídica integral e gratuita aos que comprovarem insuficiência de recursos").

5. Conferir SIQUEIRA CASTRO, Carlos Roberto de, O devido processo legal e a razoabilidade das leis na nova Constituição do Brasil, p. 34 e seguintes; BARROSO, Luis Roberto, Interpretação e aplicação da Constituição, p. 219; STUMM, Raquel Denize, Princípio da proporcionalidade no direito constitucional brasileiro, Porto Alegre: Livraria do Advogado, 1995, p. 150 e seguintes; FIGUEIREDO, Lúcia Valle, “O Estado de direito e devido processo legal”, Salvador (BA): CAJ - Centro de Atualização Jurídica, no 11, p. 4 e 6, fev. 2002. Disponível em: http://www.direitopublico.com.br/pdf_11/DIALOGO-JURIDICO-11-FEVEREIRO2002-LUCIA-VALLE-FIGUEIREDO.pdf. Acesso no dia 20 de junho de 2015. 
Se, historicamente, essas garantias foram um grande avanço para o combate ao arbítrio estatal - e são comumente lembradas -, o fato é que o devido processo legal teve outras qualidades extremamente relevantes. Como mencionamos acima, algumas - como a que resultou na construção do conceito jurídico da razoabilidade - têm sido mais exploradas doutrinariamente, mas outras, como a que impulsionou a garantia do direito de voto dos negros nos Estados Unidos da América, são praticamente ignoradas no Brasil.

Analisaremos, a seguir, essas duas virtudes do devido processo legal.

\subsection{O devido processo legal substancial e a razoabilidade}

Siqueira Castro, Barroso e Nery Junior, dentre outros, afirmam que a razoabilidade tem fundamento na cláusula do due process of law. ${ }^{6}$ Tal cláusula se desenvolveu a partir da fórmula law of the land, consagrada na Carta Magna, de 1215, documento outorgado por João "Sem Terra” para satisfazer as reivindicações dos barões feudais que buscavam limitar as ações do rei. Depois de contemplado pelas emendas V e XIV à Constituição norte-americana, ${ }^{7}$ o devido

6. Sobre a relação entre o devido processo legal e a razoabilidade, verificar, por exemplo, SIQUEIRA CASTRO, Carlos Roberto de, O devido processo legal e a razoabilidade das leis na nova Constituição do Brasil, Rio de Janeiro: Forense, 1989, especialmente p. 7-78; BARROSO, Luis Roberto, Interpretação e aplicação da Constituição, p. 218 e seguintes; NERY JÚNIOR, Nelson, Princípios do processo civil na Constituição Federal, p. 37-40.

7. A Emenda V, de 1791, tem a seguinte redação: "Ninguém será privado da vida, liberdade ou propriedade sem o devido processo legal". A emenda XIV, de 1868, ampliou a previsão para os estados integrantes da Federação norte-americana ao estabelecer: "Nenhum Estado privará qualquer pessoa da vida, liberdade ou propriedade sem o devido processo legal". Segue a redação original das Emendas XIII, XIV e XV, começando pela Emenda XIII, a que afasta a escravidão: "Section 1. Neither slavery nor involuntary servitude, except as a punishment for crime whereof the party shall have been duly convicted, shall exist within the United States, or any place subject to their jurisdiction. Section 2. Congress shall have power to enforce this article by appropriate legislation. Emenda XIV: Section 1. All persons born or naturalized in the United States, and subject to the jurisdiction thereof, are citizens of the United States and of the State wherein they reside. No State shall make or enforce any law which shall abridge the privileges or immunities of citizens of the United States; nor shall any State deprive any person of life, liberty, or property, without due process of law; nor deny to any person within its jurisdiction the equal protection of the laws. Section 2. Representatives shall be apportioned among the several States according to their respective numbers, counting the whole number of persons in each State, excluding Indians not taxed. But when the right to vote at any election for the choice of electors for President and Vice-President of the United States, Representatives in Congress, the Executive and Judicial officers of a State, or the members of the Legislature thereof, is denied to any of the male inhabitants of such State, being twenty-one years of age, and citizens of the United States, or in any way abridged, except for participation in rebellion, or other crime, the basis of representation therein shall be reduced in the proportion which the number of such male citizens shall bear to the whole number of male citizens twenty-one years of age in such State. Section 3. No person shall be a Senator or Representative in Congress, or elector of President and Vice-President, or hold any office, civil or military, under the United States, or under any State, who, having previously taken an oath, as a member of Congress, or as an officer of the United States, or as a member of any State legislature, or as an executive or judicial officer of any State, to support the Constitution of the United States, shall have engaged in insurrection or rebellion against the same, or given aid or comfort to the enemies thereof. But Congress may by a vote of two-thirds of each House, remove such disability. Section 4.The validity of the public debt of the United States, authorized by law, including debts incurred for payment of pensions and bounties for services in suppressing insurrection or rebellion, shall not be questioned. But neither the United States nor any State shall assume or pay any debt or obligation incurred in aid of insurrection or rebellion against the United States, or any claim for the loss or emancipation of any slave; but all such debts, obligations and claims shall be held illegal and void. Section 5. The Congress shall have the power to enforce, by appropriate legislation, the provisions of 
processo legal passou a se espraiar pelos ordenamentos jurídicos de outros países. ${ }^{8}$

Como já dissemos, o sentido processual do devido processo legal propiciou a proteção do direito ao contraditório e à ampla defesa, bem como das outras garantias decorrentes dessa ideia inicial. Já o devido processo legal substancial (substantive due process), nas palavras de Luis Roberto Barroso, se caracteriza como a cláusula que "enseja a verificação da compatibilidade entre o meio empregado pelo legislador e os fins visados, bem como a aferição da legitimidade dos fins. Somente presentes essas condições poder-se-á admitir a limitação a algum direito individual. Aliás, tais direitos não se limitam aos que se encontram expressamente previstos no texto, mas também incluem outros, fundados nos princípios gerais de justiça e liberdade".

Analisando sua evolução histórica, no âmbito norte-americano, é possível identificar as fases percorridas pelo devido processo legal substancial. ${ }^{10}$

A primeira delas, marcada pela ascensão e consolidação do princípio do substantive due process, tem início no fim do século XIX e se estende até a década de 1930, caracterizando-se como uma reação ao intervencionismo estatal na ordem econômica. Nessa etapa, a Suprema Corte norte-americana encampa o ideal liberal, segundo o qual o desenvolvimento deve ocorrer com a menor ingerência possível do Poder Público nos negócios privados.

A segunda fase começa com a ampliação da legislação social e de intervenção no domínio econômico levada a efeito com a eleição do presidente Franklin Roosevelt, e o consequente desprestígio do devido processo legal pela Suprema Corte, que passa a se abster de examinar o mérito das normas de cunho econômico.

E na terceira fase, que se inicia na década de 1950, o substantive due process renasce a partir da distinção entre liberdades econômicas e não econômicas. Naquele domínio (o das liberdades econômicas), o Judiciário deveria respeitar a atitude dos outros poderes. No domínio das liberdades pessoais (ou não econômicas) - como a liberdade de expressão e de religião, bem como o direito à privacidade e de participação política -, a intervenção do Judiciário continuava indispensável.

this article". Emenda XV: "Section 1. The right of citizens of the United States to vote shall not be denied or abridged by the United States or by any State on account of race, color, or previous condition of servitude. Section 2. The Congress shall have the power to enforce this article by appropriate legislation". Acessado em $1^{\circ}$ de junho de 2015: http://www.archives.gov/exhibits/charters/constitution_amendments_11-27.html.

8. A previsão na Constituição Federal brasileira encontra-se no art. $5^{\circ}$, LIV, assim redigido: "ninguém será privado da liberdade ou de seus bens sem o devido processo legal". Note-se que não há referência à vida nesse dispositivo, visto que nem obedecendo ao devido processo legal a vida pode ser suprimida do indivíduo, tendo em vista a impossibilidade jurídica de se adotar a pena de morte, com exceção do caso de guerra declarada, expressamente previsto constitucionalmente. Nesse sentido, conferir SIQUEIRA CASTRO, Carlos Roberto de, $O$ devido processo legal e a razoabilidade das leis na nova Constituição do Brasil, p. 378. Esse autor relata como se deu o surgimento da disposição constitucional sobre o devido processo legal no processo constituinte de 1987/1988.

9. Interpretação e aplicação da Constituição, p. 220.

10. BARROSO, Luis Roberto, Interpretação e aplicação da Constituição, p. 220-223; STUMM, Raquel Denize, Princípio da proporcionalidade no direito constitucional brasileiro, p. 148 e seguintes; SIQUEIRA CASTRO, Carlos Roberto de, O devido processo legal e a razoabilidade das leis na nova Constituição do Brasil, p. 7 e seguintes. STEINMETZ, Wilson, Colisão de direitos fundamentais e princípio da proporcionalidade, p. 184-185. 
O devido processo legal firma-se, então, como fundamento para o exame pelo Judiciário do mérito dos atos do Poder Público, impondo a redefinição da noção de discricionariedade. ${ }^{11}$ E, nesse sentido, cria as condições para o surgimento do princípio da razoabilidade, que nos dizeres de Linares Quintana, consiste no seguinte:

"Para determinar e decidir sobre a conformidade e adequação dos atos do Estado com a Constituição Nacional, esta, em sua letra e em seu espírito, impóe a regra da razoabilidade. Toda atividade estatal, para ser constitucional, deve ser razoável. O razoável é o oposto ao arbitrário, e significa conforme a razão, justo, moderado, prudente, tudo o que pode ser resumido em conformidade com o que dita o senso comum. $\mathrm{O}$ Congresso, o Poder Executivo e os Juízes, quando atuam no exercício de suas funções específicas, devem fazê-lo de maneira razoável. Todo ato governamental deve resistir à prova da razoabilidade. A lei que altera e, com maior razão, a que suprime o Direito cujo exercício pretende regulamentar, incorre em irrazoabilidade ou arbitrariedade se impuser limitações a este que não sejam proporcionais às circunstâncias que as motivam e aos fins a que se propóe alcançar com elas." ${ }^{\prime 2}$

Virgílio Afonso da Silva, baseado nas explicações de Willis Santiago Guerra Filho, contesta a referida origem da razoabilidade e afirma que ela não surge em 1215, uma vez que naquela ocasião falava-se em princípio da irrazoabilidade. $\mathrm{Na}$ verdade, a razoabilidade teria nascido de uma decisão judicial de 1948, proferida na Inglaterra, no caso Associated Provincial Picture Houses Ltd. versus Wednesbury Corporation, quando se passou a entender que o Judiciário poderia afastar os atos praticados por qualquer autoridade, desde que se constatasse sua absurda irrazoabilidade. Não concordamos com essa afirmação, pois, ao tratar da irrazoabilidade, também se está tratando, a contrario sensu, da razoabilidade, visto que uma é a negação da outra. Em outras palavras, irrazoável é aquilo que não é razoável, aquilo que é arbitrário. Ademais, se a decisão inglesa de 1948 autoriza o Judiciário a afastar atos irrazoáveis dos outros Poderes, o devido processo legal substancial já caminhava em sentido análogo ao fundamentar o exame pelo Judiciário do mérito dos atos do Poder Público.

Com isso, podemos afirmar que, no Brasil, o fundamento da adoção do princípio da razoabilidade estaria no art. $5^{\circ}$, inciso LIV, da Constituição Federal, que consagra o devido processo legal. ${ }^{13}$

11. Luis Roberto Barroso, Interpretação e aplicação da Constituição, p. 220 e 245.

12. LINARES QUINTANA, Segundo V. Reglas para la interpretación constitucional según la doctrina e la jurisprudencia, Buenos Aires: Plus Ultra, 1987, p. 122-123.

13. Com base no entendimento de Luis Roberto Barroso, que não faz distinções claras entre a razoabilidade e a proporcionalidade, conferir, por exemplo, a decisão proferida no dia 2 de agosto de 2001 pelo Supremo Tribunal Federal, na Ação Direta de Inconstitucionalidade n 2.019-6/MS, relatada pelo ministro Ilmar Galvão. Na ocasião, o Tribunal Pleno, vencido o ministro Marco Aurélio, considerou inconstitucional a Lei n 1.949/99, do Estado do Mato Grosso do Sul, que instituía, no âmbito do Poder Executivo, um programa de pensão mensal às crianças geradas a partir de estupro, por falta de razoabilidade, com base no art. $5^{\circ}$, inciso LIV, da Constituição Federal. 


\subsection{O devido processo legal e o voto dos negros}

Como já afirmamos, o devido processo legal tem como marco histórico a Carta Magna de 1215. Sua maturidade, no Brasil, se deu com Constituição de $1988 .{ }^{14}$

No entanto, um traço bastante significativo desta garantia passa praticamente ao largo da doutrina especializada: $:^{15}$ a relação entre o direito ao sufrágio dos negros e as Emendas XIII, XVI e XV à Constituição dos Estados Unidos da América. ${ }^{16}$

Celso Ribeiro Bastos ${ }^{17}$ enuncia a aplicação do devido processo legal e aborda o surgimento da Emenda XIV à Constituição norte-americana citando como "a aplicação mais natural introduzida" por ela como a de permitir a integração racial nos anos de 1960.

Pinto Ferreira, ${ }^{18}$ de igual modo, refere-se à Emenda XIV como "princípio da igualdade perante a lei", baseando-se na "igualdade de condições e de circunstâncias".

Crettela Júnior ${ }^{19}$ limita-se à tradução do due process of law, sem maiores incursões históricas.

Luiz Alberto David Araújo e Vidal Serrano ${ }^{20}$ afirmam, de certa forma, a redundância da Emenda XIV ao repisar o princípio do devido processo legal da já previsto na Emenda V, sendo a "finalidade essencial" do devido processo legal substantivo a de servir para o controle de constitucionalidade.

Pariz, ${ }^{21}$ de igual modo, afirma que a Emenda V foi "convertida" na Emenda XIV e que o devido processo legal no seu sentido substantivo se fixa com a tutela das minorias étnicas e econômicas pela Corte Warren (1950-1960). Miranda ${ }^{22}$ trata as Emendas V e XIV como instituidoras do due process of law.

14. Para a descrição do itinerário desta garantia, conferir PEREGRINO FERREIRA, Marcelo Ramos. “O controle de convencionalidade da Lei da Ficha Limpa. Direitos Políticos e Inelegibilidades". Rio de Janeiro: Lumen Juris, 2015.

15. Demonstraremos isso nos próximos parágrafos, mas destacamos aqui duas exceções. Siqueira Castro aponta que "as emendas 13, 14 e 15 (foram) destinadas fundamentalmente a garantir direitos de cidadania e as liberdades civis (civil liberties) aos ex-escravos e seus descendentes de cor negra". CASTRO, Carlos Roberto de Siqueira. O Devido Processo Legal e a Razoabilidade das Leis na Nova Constituição do Brasil. 5 a ed. Rio de Janeiro: Forense, 2010, p. 24. Abordando o caso específico do devido processo substancial e o tema da escravidão em Dred Scott, ver também SILVEIRA, Paulo Fernando. Devido processo legal: Due process of Law. Belo Horizonte: Livraria Del Rey, 2001, p. 418-420.

16. Para a transcrição dos debates parlamentares no Senado, vide FERBER, Daniel e SHERRY, Suzanna. A History of the American Constitution. Minnesota: West Publishing Company, p. 297-319, 1990.

17. BASTOS, Celso Ribeiro e MARTINS, Ives Gandra. Comentários à Constituição do Brasil. $1^{\text {a }}$ ed. São Paulo: Saraiva, 1989, p. 262.

18. FERREIRA, Pinto. Curso de Direito Constitucional. $5^{a}$ ed. São Paulo: Saraiva, 1991, p. 143.

19. CRETELLA JÚNIOR, J. Comentários à Constituição 1988. Rio de Janeiro: Forense Universitária, 1988, p. 530 .

20. ARAUJO, Luiz Alberto David de e NUNES JUNIOR, Vidal Serrano. Curso de Direito Constitucional. $17^{\text {a }}$ ed. São Paulo: Verbatim, 2012, p. 237-239.

21. PARIZ, Ângelo Aurélio Gonçalves. O princípio do devido processo legal: direito fundamental do cidadão. Coimbra: Almedina, 2009, p. 84-85.

22. MIRANDA, Antonio Fernando e MIRANDA, Fernanda Barreto, "O Devido Processo Legal e a Constituição Brasileira de 1988". Revista de Julgados do Tribunal de Alçada Criminal do Estado de São Paulo, São Paulo, v. 39, p.18, jul. 1998. 
Maciel $^{23}$ acentua uma abrangência maior da emenda 14, em relação à Emenda V, constituindo-se a primeira como uma "salvaguarda mais explícita de proibição da iniquidade". Aponta ter sido somente em 1921 a primeira menção à intima relação entre ambas as emendas, no precedente do Juiz Willian Taft (Truax v. Corrigan).

Oliveira, ${ }^{24}$ embora reconheça que as Emendas XIII, XIV e XV destinaram-se "a garantir os direitos de cidadania aos ex-escravos e descendentes de cor negra", igualmente situa o devido processo substancial na Corte Warren.

Para Del Claro, o escopo da Emenda XIV era permitir, no âmbito estadual, a imposição das garantias já consagradas na Emenda V, cuja incidência era, precipuamente, na Jurisdição Federal.

A Emenda XIV, também para Brindeiro, ${ }^{25}$ apenas vincula os Estados ao devido processo legal adrede afirmado para a União pela Emenda V, sendo tal alteração fonte da atuação da Corte Warren na proteção dos direitos civis na década de 60.

Observa-se das colações acima que inexiste na doutrina especializada a relação direta entre as emendas mencionadas e o direito à inclusão da população negra nos Estados Unidos.

A cláusula do devido processo legal, ${ }^{26}$ tal qual inscrita na Emenda $\mathrm{V}$ da Bill of Rights, se integrou às primeiras dez emendas incorporadas à Constituição estadunidense em abril de 1791 e fez constar também a advertência que ninguém poderia "ser privado da vida, liberdade, ou bens, sem processo legal". A propriedade também não poderia "ser expropriada para uso público sem justa indenização." ${ }^{27}$

Esta garantia, todavia, não permitiu a emancipação da pessoa negra na sociedade americana. Ao revés, em precedente de bastante relevância, o devido processo legal foi usado como fundamento para se declarar a inconstitucionalidade da proibição da escravidão. Neste caso específico, o devido processo legal serviu para manter a escravidão de Dred Scott.

Com efeito, Dred Scott teve seu dia na Corte, quando, em março de 1857, a Suprema Corte dos Estados Unidos foi chamada a decidir o seu caso. Por sucessão, o escravo Dred

23. MACIEL, Adhemar Ferreira. “O devido processo legal e a constituição brasileira de 1988”. Revista de Julgados do Tribunal de Alçada do Estado de Minas Gerais, Belo Horizonte, v. 68, jul. 1997, p. 38.

24. OLIVEIRA, Cybelle. "Devido Processo Legal". Revista de Direito Constitucional e Internacional, São Paulo, ano 8, n. 32, jul./set. 2000, p. 182.

25. BRINDEIRO, Geraldo."O Devido Processo Legal e o Estado Democrático de Direito". Arquivos do Ministério da Justiça, Brasília: Ministério da Justiça, ano 49, n. 188, p. 33, jul./dez. 1996, p. 33.

26. No texto original, no art. 1, seção 2 já estavam garantidos o habeas corpus e as proibições do bill of attainder e de leis ex post facto. (http:// constitutionus.com/): Acessado em 4 de maio de 2015.

27. Amendment V- No person shall be held to answer for a capital, or otherwise infamous crime, unless on a presentment or indictment of a Grand Jury, except in cases arising in the land or naval forces, or in the Militia, when in actual service in time of War or public danger; nor shall any person be subject for the same offence to be twice put in jeopardy of life or limb; nor shall be compelled in any criminal case to be a witness against himself, nor be deprived of life, liberty, or property, without due process of law; nor shall private property be taken for public use, without just compensation". Disponivel em: http://www.archives.gov/exhibits/charters/bill_of_rights_transcript. html. Acesso em: 13 de maio 2015. Tradução nossa: "Ninguém será detido para responder por um crime capital ou infamante, salvo por denúncia ou acusação perante um Grande Júri, exceto nos casos decorrentes de forças terrestres ou navais, ou na milícia, quando em serviço ativo em tempo de guerra ou de perigo público, nem qualquer pessoa pode ser sujeitada ao julgamento pelo mesmo crime duas vezes, ao perigo de vida ou de ferimentos graves, nem ser obrigado em qualquer processo criminal a servir de testemunha contra si mesmo, nem ser privado da vida, liberdade ou bens sem o devido processo legal; nem a propriedade privada poderá ser expropriada para uso público, sem justa indenização". 
Scott foi adquirido pela esposa de um cirurgião. Dred Scott arguiu, então, que seu serviço num Estado que não permitia a escravidão, fazia dele um homem livre ${ }^{28}$. A decisão fincou-se em três argumentos principais, em desfavor da pretensão do autor : i) os negros, mesmo aqueles libertos, não são cidadãos dos Estados Unidos; ii) Dred Scott não havia se tornado um homem livre, em razão de sua residência num Estado, onde vigorara a abolição, pois as disposições do Congresso Nacional não poderiam afastar a legislação do Estado escravocrata; iii) Dred Scott não se tornara um homem livre, em face de seu retorno para o Estado escravocrata de origem (Missouri). A questão dramática nesta decisão, segundo Bernard Schwartz, ${ }^{29}$ além de ter ajudado a promover a Guerra Civil é o fato de a Suprema Corte ter negado o direito dos negros à cidadania americana, bem assim a afirmação da ausência de poderes do Congresso de interferir nos Estados adeptos da escravidão.

E a concepção deste precedente repousava, de forma expressa, exatamente na impossibilidade de o Congresso Nacional admoestar os direitos de propriedade assegurados pelo devido processo legal insculpido na Emenda V. No precedente restou claro que o fato de a União possuir ascensão sobre um determinado território não poderia redundar na perda da propriedade dos particulares ali residentes, por ofensa ao devido processo legal. O Compromisso de Missouri, que assinalava o fim da escravidão em parte dos Estados Unidos, nesta decisão foi julgado inconstitucional em nome do devido processo legal.

Mais tarde e somente após a Guerra Civil Americana (1861-1865), em 1866, sobreveio a Emenda XIV, como uma resposta clara e direta ao Caso Dred Scott, ${ }^{30}$ assegurando aos cidadãos, em face dos Estados, a mesma garantia, mais alargada, ${ }^{31}$ não sem alguma restrição da

\footnotetext{
28. A semelhança com o precedente inglês impressiona. Em 1772, James Sommerset, nascido na África, foi comprado por uma pessoa de nome Stewart, tendo fugido do cativeiro na cidade de Londres. Recusando-se a retornar ao serviço, foi recapturado. A bordo de navio para a Jamaica, o lobby antiescravagista londrino deu-lhe suporte e a impetração de um bem-sucedido habeas corpus foi deferido por Lord Mansfield. BINGHAM, Tom. The Rule of the Law. London: Penguin Group, p. 56, 2010.

29. SCHWARTZ, Bernard. A History of the Supreme Court. New York/NY: Oxford University Press, p. 113-115, 1993.

30. A seção 1 da emenda preconiza que todas as pessoas nascidas nos Estados Unidos são consideradas cidadãs.

31."Amendment XIV, Section 1. All persons born or naturalized in the United States, and subject to the jurisdiction thereof, are citizens of the United States and of the State wherein they reside. No State shall make or enforce any law, which shall abridge the privileges or immunities of citizens of the United States; nor shall any State deprive any person of life, liberty, or property, without due process of law; nor deny to any person within its jurisdiction the equal protection of the laws." Disponivel em: http://www.archives.gov/exhibits/charters/bill_of_rights_transcript. html. Acesso em: 13 de maio de 2015. Tradução nossa: "Todas as pessoas nascidas ou naturalizadas nos Estados Unidos, e sujeitas à sua jurisdição, são cidadãos dos Estados Unidos e do Estado onde residem. Nenhum Estado poderá fazer ou executar qualquer lei que restrinja os privilégios ou imunidades dos cidadãos dos Estados Unidos, nem qualquer Estado pode privar qualquer pessoa da vida, liberdade ou propriedade, sem o devido processo legal, nem negar a qualquer pessoa dentro de sua jurisdição a igual proteção das leis".
} 
Corte Suprema norte-americana. ${ }^{32} \mathrm{~A}$ Emenda XIV, de forma direta, afirma que todos aqueles nascidos ou naturalizados nos Estados Unidos são cidadãos e que nenhum Estado poderá aprovar legislação que afaste os "privilégios e imunidades" relacionados a esta cidadania. ${ }^{33}$

A Emenda XIV, conforme Lúcia do Valle Figueiredo, representou uma "grande transformação" no devido processo legal: $:^{34}$ "isso porque já não mais se fala, apenas, do devido processo legal, mas na igual proteção da lei, equal protection of law. Então, depois da Emenda no 14 , sobretudo com a aplicação que a Suprema Corte Americana faz da cláusula, dá-se abrangência muito maior. $\mathrm{O}$ devido processo legal passa a significar a "igualdade na lei", e não só "perante a lei".

Como já observamos, a doutrina tem uma apreciação um tanto asséptica do fenômeno, como se a cláusula da equal protection of law fosse um avanço exclusivamente de índole processual, haurida no Parlamento estadounidense, sem maiores reflexos da vida cotidiana, abstraindo-se a riqueza de uma luta histórica e concreta.

No entanto, a introdução da Emenda XIV obedece à continuidade do mote da Guerra Civil, agora travado nas Cortes de Justiça e no Poder Legislativo, mormente, uma guerra de posição e de conceitos travada entre o Poder Federal e os Estados verdadeiramente autônomos na Federação americana. É que a Constituição dos Estados Unidos prescrevia que as eleiçôes dos representantes dar-se-ia nos "tempos, lugares e modos" ${ }^{\prime 35}$ designados pelo Legislativo de cada Estado. Este dispositivo permitiu uma autonomia dos entes federados que barrou os avanços relacionados ao voto dos negros.

A nascença dessas emendas é de curial importância para o desenvolvimento do direito ao voto das minorias, havendo mais sangue e disputa que o relato do processo legislativo de

32. Decisão da Suprema Corte dos Estados Unidos, num primeiro momento, não aceitava a submissão dos Estados às dez emendas. Este entendimento se baseou no fato histórico de que as emendas representaram freio ao poder nacional, razão pela qual o poder central continuou a ser limitado no que diz respeito à restrição da legislação estadual (Barron v. Mayor and City Council of Baltimore, 32 U. S. (7 Pet.) 243, 8 L.Ed. 672 (1.833). A Suprema Corte dos Estados Unidos continua rejeitando a tese de total incorporação do Bill of Rights, por meio da Emenda XIV. A tese que tem prevalecido é a teoria da incorporação seletiva (theory of selective incorporation), na qual somente aquelas provisões consideradas fundamentais para o sistema de direito americano são aplicáveis ao Estados, via devido processo da Emenda XIV. United States v. Cruikshank, 92 U.S. (2 Otto) 542, 553, 23 L. Ed. 588 (1876). Destarte, das primeiras oito emendas, o mesmo tribunal, explicitamente, entendeu que três delas não se aplicam aos Estados: i) o direito de portar armas da Emenda II; ii) a 5 a cláusula quando garante o indiciamento tão só após o grande júri; iii) e a garantia do julgamento pelo júri no caso de uma ação civil (Emenda VII). NOWAK, John E.; ROTUNDA, Ronald D. Constitutional Law. Minnesota: West Publishing CO., 1995, p. 340-341.

33. Colhe-se da seção 2 da emenda: "All persons born or naturalized in the United States, and subject to the jurisdiction thereof, are citizens of the United States and of the State wherein they reside. No State shall make or enforce any law, which shall abridge the privileges or immunities of citizens of the United States." Acessado no dia 10 de junho de 2015 (http://www.archives.gov/exhibits/charters/constitution_amendments_11-27.html).

34. FIGUEIREDO, Lúcia Valle."Estado de Direito e Devido Processo Legal”, p. 3.

35. Tradução livre do excerto do art. IV: “Section. 4. The Times, Places and Manner of holding Elections for Senators and Representatives, shall be prescribed in each State by the Legislature thereof; but the Congress may at any time by Law make or alter such Regulations, except as to the Places of chusing Senators. Acessado em $1^{\circ}$ de junho de 2015: www.archives.gov/exhibits/charters/constitution_transcript.html. 
alteração de uma regra processual. ${ }^{36}$ Vencida a Guerra Civil, cujo objetivo expresso fora a derrocada da escravidão pela União, para uma escravocrata Confederação de muitos Estados, restava a implementação da igualdade também na vida daqueles recém-libertos. ${ }^{37} \mathrm{E}$ a potencialidade desta Emenda está em representar um fundamento jurídico para a ascensão de outras minorias políticas como as mulheres, os homossexuais e os indígenas, em contraposição à timidez da Emenda V.

A Emenda XIII, além da proscrição da escravidão, invalidou a fórmula para a definição da representação no Congresso que contava um escravo como $3 / 5^{38}$ de qualquer outro homem. $\mathrm{O}$ Ato Civil de 1866 declarou todos os descendentes de africanos nos Estados Unidos como cidadãos americanos. E aí afirma Richard Claude: "Os republicanos no Congresso tentaram elevar os princípios dos Atos de Direitos Civis para o status de emenda constitucional: a Emenda XIV que foi adotada em 1868. O significado para o negro foi o seu reconhecimento como pessoa e a aquisição da cidadania plena, com os 'privilégios e imunidades' da cidadania americana. Historicamente, as cláusulas do devido processo legal e da igual proteção foram as únicas partes das emendas a serem efetivamente empregadas para salvaguarda do sufrágio negro." ${ }^{39}$

Em 1875, logo após a Emenda XIV (1868), que definira que todas as pessoas que moram nos Estados Unidos sujeitam-se à sua jurisdição, sendo vedada a negativa ao usufruto dos "privilégios e imunidades" dos cidadãos americanos pelos Estados, houve a tentativa de assegurar o voto às mulheres, direito não reconhecido no Estado do Missouri. A Suprema Corte, então, nas palavras do juiz Waite, declinou do pedido de Francis Minor, em Minor v. Happersett, afirmando que a cidadania não necessariamente coincide com o direito ao voto. Neste contexto, restou decidido que "a Constituição não confere o direito ao voto para ninguém". A interpretação dada pelo juiz Waite acolheu a percepção de que caberia aos Estados a definição sobre a qualificação dos eleitores, permitindo-se, assim, a manutenção da inelegibilidade das mulheres.

Em 1888, um inspetor das eleições (federais) decidiu destruir algumas urnas com resultado desfavorável às suas pretensóes. Em sede de habeas corpus, a Suprema Corte, então, negou

36. Alguns dados sobre a violência contra os negros neste período da vida americana: entre abril e novembro de 1868, durante as eleições estaduais e para presidente, de acordo com uma investigação do Congresso, foram assassinadas 1081 pessoas, sendo a maioria negra. E mais, segundo Kousser:"Quarenta e seis negros foram massacrados em Memphis e 34 em Nova Orleans em 1866; 25 a 30 em Meridian, Mississipi em 1871, e 35 em Vicksburg em 1874; e 105 na pequena cidade de Colfax, Louisiana, num domingo de Páscoa, 1873, incluindo em torno de 40 que baixaram suas armas e se renderam.. KOUSSER, J Morgan. "Voting Rights Act and the Two Reconstructions" in GROFMAN, Bernard, DAVIDSON, Chandeler. "Controversies in Minority Voting-The Voting Rights Act in Perspective". Washington: The Brookings Institution, 1992, p. 142.

37. Daniel Ferber e Suzanna Sherry dão conta da existência, em muitos Estados do Sul, dos chamados black codes, incluindo proibições de os negros alugarem terras e circularem livremente, dentre outras sanções, inclusive como reprimendas de ordem criminal. FERBER, Daniel e SHERRY, Suzanna. A History of the American Constitution. Minnesota: West Publishing Company, p. 298, 1990.

38. Art. 1', Seção 2, na redação original: “3: Representatives and direct Taxes shall be apportioned among the several States which may be included within this Union, according to their respective Numbers, which shall be determined by adding to the whole Number of free persons, including those bound to Service for a Term of Years, and excluding Indians not taxed, three fifths of all other Persons (...)" (http://constitutionus. com/). Acessado em 6 de maio de 2015.

39. CLAUDE, Richard. The Suprem Court and the Electoral Process. Baltimore: Jonh Hopkins Press, 1970, p. 45. 
o writ para afirmar que o inspetor, naquela qualidade, numa eleição federal, deveria responder, igualmente, pelas sanções previstas na lei nacional e não somente, como alegara a defesa, por aquelas admoestações paroquiais derivadas de sua condição de servidor público estadual. Este precedente alargou a competência do Congresso para a atuação nas eleições ocorridas nos Estados e por eles regulados, de acordo com o tempo e a forma próprios.

A cassação dos direitos dos negros ao sufrágio, mesmo após as Emendas XIII, XIV e XV, deu-se, basicamente, segundo o relato de Richard Claude, nesta batalha de competências entre os entes federados: enquanto alguns Estados e particulares barravam negros nas diversas fases do processo eleitoral, o Poder central federal tentava alargar sua autoridade para impedir a vulneração dos direitos e garantias individuais da população negra. Pode-se classificar as dificuldades apresentadas, de acordo com o mesmo autor: i) no afastamento da população negra da participação das eleições primárias; ii) na manipulação da realização de testes de alfabetização para os eleitores; iii) na imposição da adimplência de taxas para o exercício do voto e, finalmente, iv) na discriminação pela manipulação dos distritos, de acordo com critérios raciais, o famoso gerrymandering, ${ }^{40}$ enriquecido com o fator da cor.

E mesmo quando assegurado o direito ao sufrágio em dez dos Estados do Sul pelo Ato Militar de Reconstrução de 1867, no exemplo de Kousser, ${ }^{41}$ democratas brancos do Estado da Geórgia fizeram valer o entendimento que o voto não implicava a assunção de cargo público para expulsar todos os negros eleitos para a legislatura posterior.

Observa-se que os contornos políticos do direito ao sufrágio dos negros e de suas liberdades públicas nos Estados Unidos beberam no binômio ballot/bench, ou seja, dividiram-se entre o exercício do voto na urna (ballot) e a sua judicialização (bench)..$^{42} \mathrm{O}$ papel da Suprema Corte daquele país na construção da democracia é um fato inquestionável, sendo a judicialização da política um instrumento vigoroso de sua transformação.

Finalmente, é necessário que se resgate o quão importante foi a luta das minorias étnicas nos Estados Unidos pelo sufrágio para o aprimoramento e surgimento da cláusula do devido processo legal das Emendas XIV e XV da Constituição norte-americana, hoje instrumento de defesa de todos os cidadãos, consagrado na Constituição Brasileira de 1988.

\footnotetext{
40. A expressão é usada para apontar a manipulação dos limites territoriais dos distritos eleitorais, de acordo com os interesses de alguém. Virgílio Afonso da Silva explica:"nome dado por um editor norte-americano que, ao ouvir de um cartunista de seu jornal que o desenho do distrito de Essex, Massachusetts, assemelhava-se a uma salamandra (salamander), respondeu que seria melhor chamá-lo de gerrymander, fazendo um trocadilho com o nome do responsável pelo novo desenho do distrito, o governador do Massachusetts, Elbridge Gerry". SILVA, Virgílio Afonso da. Sistemas eleitorais: tipos, efeitos jurídico-politicos e aplicação ao caso brasileiro. São Paulo: Malheiros, 1999, p. 43.
}

41. KOUSSER, J Morgan. "Voting Rights Act and the Two Reconstructions" in GROFMAN, Bernard, DAVIDSON, Chandeler. "Controversies in Minority Voting-The Voting Rights Act in Perspective". Washington: The Brookings Institution, 1992, p. 135.

42. CLAUDE, Richard. The Suprem Court and the Electoral Process. Baltimore: Jonh Hopkins Press, p. 45, 1970. 


\section{Conclusões}

Como procuramos demonstrar, se o devido processo legal já teria uma importância histórica relevantíssima ao se revelar como uma garantia dos direitos das partes nos processos judiciais ou administrativos (procedural due process), ele, na verdade, foi muito além.

Mostrou-se fundamental para combater o arbítrio do Estado - quando se desenvolveu a ideia do substantive due process -, permitindo que o Judiciário analisasse o mérito dos atos do Poder Público, criando condições para que surgisse o princípio da razoabilidade.

Mas pouco se falou - ao menos aqui no Brasil - sobre a valiosa contribuição que o devido processo legal deu para combater a desigualdade racial e para que um outro direito fundamental fosse exercido em sua plenitude: $\mathrm{o}$ direito ao voto. ${ }^{43}$

Portanto, dos vários ângulos pelos quais se analisa o devido processo legal percebe-se como ele se mostra intrinsicamente vinculado à ideia de democracia. A história desta não pode ser escrita sem mencionar aquele. Claramente, não há democracia sem respeito ao devido processo legal.

\section{Referências}

ARAUJO, Luiz Alberto David de e NUNES JUNIOR, Vidal Serrano. Curso de Direito Constitucional. 17a ed. São Paulo: Verbatim, 2012.

BARROSO, Luis Roberto. Interpretação e aplicação da Constituição: fundamentos de uma dogmática constitucional transformadora. $6^{a}$ ed. São Paulo: Saraiva, 2004.

BASTOS, Celso Ribeiro Bastos e MARTINS, Ives Gandra. Comentários à Constituição do Brasil. $1^{\text {a }}$ ed. São Paulo: Saraiva, 1989.

BINGHAM, Tom. The Rule of the Law. London: Penguin Group, 2010.

BRINDEIRO, Geraldo. "O Devido Processo Legal e o Estado Democrático de Direito”. Arquivos do Ministério da Justiça, Brasília: Ministério da Justiça, ano 49, n. 188, jul./dez. 1996.

CLAUDE, Richard. The Suprem Court and the Electoral Process. Baltimore: Jonh Hopkins Press, 1970.

CRETELLA JÚNIOR, J. Comentários à Constituição 1988. Rio de Janeiro: Forense Universitária, 1988.

43. Trata-se, obviamente, de uma via de mão dupla. Como dissemos acima, a luta das minorias étnicas nos Estados Unidos da América pelo sufrágio foi de fundamental importância para o aprimoramento e surgimento da cláusula do devido processo legal das Emendas XIV e XV da Constituição norte-americana. 
FERBER, Daniel e SHERRY, Suzanna. A History of the American Constitution. Minnesota: West Publishing Company, p. 297-319, 1990.

FERREIRA, Pinto. Curso de Direito Constitucional. 5ª ed. São Paulo: Saraiva, 1991.

FIGUEIREDO, Lúcia Valle. "Estado de Direito e Devido Processo Legal". Revista Diálogo Jurídico, Salvador (BA): CAJ - Centro de Atualização Jurídica, no 11, fev. 2002. Disponível em: http://www.direitopublico.com.br/pdf_11/DIALOGO-JURIDICO-11-FEVEREIRO-2002-LUCIA-VALLE-FIGUEIREDO.pdf. Acesso no dia 20 de junho de 2015.

KOUSSER, J. Morgan. "Voting Rights Act and the Two Reconstructions" in GROFMAN, Bernard, DAVIDSON, Chandeler. "Controversies in Minority Voting-The Voting Rights Act in Perspective". Washington: The Brookings Institution, 1992.

LINARES QUINTANA, V. Reglas para la interpretación constitucional según la doctrina e la jurisprudencia, Buenos Aires: Plus Ultra, 1987.

MACIEL, Adhemar Ferreira. "O devido processo legal e a constituição brasileira de 1988”. Revista de Julgados do Tribunal de Alçada do Estado de Minas Gerais, Belo Horizonte, v. 68, jul. 1997.

MIRANDA, Antonio Fernando e MIRANDA, Fernanda Barreto. "O Devido Processo Legal e a Constituição Brasileira de 1988". Revista de Julgados do Tribunal de Alçada Criminal do Estado de São Paulo, São Paulo, v. 39, jul. 1998.

NERY JÚNIOR, Nelson. Princípios do processo civil na Constituição Federal. $7^{\text {a }}$ ed. Só Paulo: Revista dos Tribunais, 2002.

NOWAK, John E.; ROTUNDA, Ronald D. Constitutional Law. Minnesota: West Publishing CO. 1995.

OLIVEIRA, Cybelle. "Devido Processo Legal”. Revista de Direito Constitucional e Internacional, São Paulo, ano 8, n 32, jul./set. 2000.

PARIZ, Ângelo Aurélio Gonçalves. O principio do devido processo legal: direito fundamental do cidadão. Coimbra: Almedina, 2009.

PEREGRINO FERREIRA, Marcelo Ramos. O controle de convencionalidade da Lei da Ficha Limpa. Direitos Politicos e Inelegibilidades. Rio de Janeiro: Lumen Juris, 2015.

SCHWARTZ, Bernard. A History of the Supreme Court. New York/NY: Oxford University Press, 1993.

SILVEIRA, Paulo Fernando. Devido processo legal: due process of law. Belo Horizonte: Livraria Del Rey, 2001. 
SIQUEIRA CASTRO, Carlos Roberto de. O devido processo legal e a razoabilidade das leis na nova Constituição do Brasil. $5^{\mathrm{a}}$ ed. Rio de Janeiro: Forense, 2010.

STEINMETZ, Wilson. Colisão de direitos fundamentais e princípio da proporcionalidade. Porto Alegre: Livraria do Advogado, 2001.

STUMM, Raquel Denize. Princípio da proporcionalidade no direito constitucional brasileiro. Porto Alegre: Livraria do Advogado, 1995.

SILVA, Virgílio Afonso da Silva. Sistemas eleitorais: tipos, efeitos jurídico-políticos e aplicação ao caso brasileiro. São Paulo: Malheiros, 1999. 
Recebido em: 19/09/2015

Aceito em: 30/09/2015

\section{Como citar}

FERREIRA, Marcelo Ramos Peregrino; SILVA, Roberto Baptista Dias da. $O$ devido processo legal e suas potencialidades: $o$ caso do direito de voto dos negros nos Estados Unidos da América. Ballot. Rio de Janeiro: UERJ. Volume 1 Número 2 Setembro/Dezembro 2015. pp. 280-295. Disponível em: [http://www.e-publicacoes.uerj.br/index.php/ballot]

\section{c) (1) (3)}

A Revista Ballot está licenciada sob uma licença Creative Commons Atribuição - Não Comercial - Compartilha Igual 3.0 Não Adaptada. 